\title{
PERCEPÇÃO DOS MORADORES E FATORES DE ATRAÇÃO EM CIDADES MÉDIAS DINÂMICAS
}

\author{
attraction factors in dynamic medium-sized cities of Brazil according to perception of residents
}

Ralfo Matos *

\begin{abstract}
Resumo
Esse estudo discute os fatores que explicam a fixação de migrantes e não-migrantes em cidades médias dinâmicas do Brasil atual. Considerados os fatores econômico-sociais, geoculturais e culturais, pesquisa de campo realizada em 55 cidades de diferentes regiões concluiu, de forma surpreendente, que os fatores culturais foram os mais relevantes, ultrapassando os fatores econômicos na maioria das cidades pesquisadas. As razões destacadas pelos entrevistados indicam que "apego à família, vizinhança e tranqüilidade" é um valor proeminente assim como "educação, saúde e serviços básicos”. Os fatores econômico-sociais comparecem em seguida, sendo muito destacados pelos habitantes do Sul e Sudeste brasileiros. Já os fatores geoculturais foram valorizados por cerca de $20 \%$ dos respondentes, o que sugere a necessidade de se pensar em políticas públicas que levem em conta itens como relações de vizinhança, entretenimento e atrativos paisagísticos, elementos da subjetividade humana estudados há muito tempo pela Geografia Cultural.
\end{abstract}

Palavras-chaves: Geografia, Cidades médias, Geografia cultural, Percepção urbana.

\begin{abstract}
This study discusses the factors that explain the fixation of migrants and non-migrants in the dynamic secondary cities of the actual Brazil. Considering the economic and social factors and the geographic-cultural and cultural factors, the field research developed in 55 cities from different regions concluded, surprisingly, that cultural factors were the most relevant, surpassing the economic factors in the majority of the cities researched. The reasons pointed by the respondents indicate that "attachment to the family, neighborhood and peacefulness" is a prominent value as well as "education, health and basic services". The economic-social factors appear in sequence, mostly emphasized by the inhabitants of southern and southeastern Brazil. The geographic-cultural factors, on the other hand, were valued by around $20 \%$ of the respondents. This suggests the need of thinking in public policies that take into account issues like neighborhood relations, entertainment and landscape attractions, elements of human subjectivity that have been studied in Cultural Geography for a long time.
\end{abstract}

Key words: Geography, Secondary cities, Cultural geography, Urban perception.

\section{Resumen}

Este estudio reflexiona sobre los factores que explican el establecimiento de migrantes y no migrantes en ciudades medias dinámicas del Brasil actual. Considerando los factores económico-sociales, geoculturales y culturales, la investigación realizada en 55 ciudades de diferentes regiones concluyó, de manera sorprendente, que los factores culturales fueron los más relevantes, sobrepasando los factores económicos en la mayoría de las ciudades investigadas. Las razones destacadas por los entrevistados indican que "cariño por la familia, vecindad y tranquilidad" es un valor prominente, así como "educación, salud y servicios básicos". Los factores económico-sociales comparecen en seguida, siendo muy destacados por los habitantes del Sur y Sudeste brasileños. Ya los factores geoculturales fueron valorados por cerca de $20 \%$ de los que contestaron a la encuesta, lo que sugiere la necesidad de pensarse en políticas públicas que tomen en cuenta ítemes como las relaciones de vecindad, el entretenimiento y los atractivos paisajísticos, elementos de la subjetividad humana que han sido estudiados por la Geografía Cultural desde hace mucho tiempo.

Palabras clave: Geografia, Ciudades medias, Geografia cultural, Percepcion urbana..

(*) Bolsista Produtividade do CNPq e Prof. Dr. da Universidade Federal de Minas Gerais - Av. Antônio Carlos 6627, CEP: 31270901 - Belo Horizonte (MG), - Brasil, Tel: (+55 31) 34995426 - ralfomatos@yahoo.com.br 


\section{INTRODUÇÃO}

Após vários estudos dedicados à questão da desconcentração demográfica no Brasil com base em dados secundários, surgiu a necessidade de aprofundar as análises por meio de pesquisa direta em localidades que vinham participando do processo de desconcentração. Sabíamos que a dispersão da população no espaço geográfico era seletiva, contemplava as cidades intermediárias mais bem equipadas e relativamente próximas das grandes metrópoles, alcançando também localidades dispersas de regiões do país, como o Nordeste, Norte e Centro Oeste. Subespaços que vinham recebendo novas plantas industriais, grandes empresas estatais, investimentos na agroindústria e no setor de turismo tornavam-se pólos de atração de trabalhadores migrantes e de pequenos negócios no comércio e nos serviços.

Os dados vinham mostrando que o emprego formal desconcentrava-se geograficamente, embora de forma menos abrangente que a população. O emprego com carteira assinada expandia mais fortemente nas cidades que compõem o arco de influência dos principais centros urbanos do país, particularmente no Sudeste e no estado de São Paulo, enquanto uma fração expressiva do crescimento populacional verificado no Centro Oeste, Norte e Nordeste não se explicava, tão somente, pelo crescimento do emprego formal. Se a desconcentração demográfica pode ser analisada por meio de dados de fluxos migratórios, convém ressaltar que os migrantes movem-se no espaço em busca de oportunidades difusas, nem sempre conhecidas, e o emprego formal é apenas uma delas, já que é alta a proporção de trabalhadores ocupados no setor informal. Por tudo isso, é sempre conveniente verificar quais são os municípios que mais atraem migrantes, já que essa atração deve se apoiar em algum tipo de oferta de trabalho. No caso dos municípios dinâmicos acima referidos, é certo que o crescimento demográfico sustentado pela imigração, acompanha-se tanto do incremento do emprego formal quanto do informal. Em Matos (2005) mostramos que as participações relativas dos imigrantes empregados na maioria dos municípios dinâmicos apresentavam-se mais bem distribuídas no país, em decorrência da densificação da rede urbana brasileira e da significativa melhora da infraestrutura dos municípios de porte intermediário. A generalização da transição demográfica reduziu os níveis de pressão do campo sobre a cidade, o que representou alteração do sentido das correntes migratórias, após mais de meio século de êxodo rural. Desde a década de 1970, predomina a migração cidade-cidade, o que veio reforçar a expansão da rede urbana do país e dar fluidez ao processo de desconcentração demográfica. Assim, a migração tornou-se também uma componente central para o entendimento do processo de dispersão econômico-populacional nas últimas três décadas.

Estudo recente, com base nos dados do emprego formal (dados da RAIS ), constata a existência de dois vetores espaciais de crescimento no primeiro decênio do século XXI: o primeiro, considerando a configuração atual da rede urbana, põe em destaque os municípios de porte intermediário; o segundo, considerando as atuais divisões regionais, ressalta o dinamismo das regiões Norte e Centro-Oeste. A indústria e a agropecuária figuram entre as atividades motoras desse dinamismo, o que demonstra que as atividades produtivas constituem um dos sustentáculos do processo de interiorização do crescimento demográfico e econômico. A despeito das limitações da base de dados utilizada, o crescimento do emprego verificado amplia a presença de trabalhadores "migrantes" no mercado formal nos municípios dinâmicos do Centro Oeste e Norte, confirmando a importância da migração inter-regional. Além disso, o estudo explicitou uma dicotomia: os municípios dinâmicos tendem a atrair tanto trabalhadores qualificados, muitos com formação superior, quanto imigrantes de baixa qualificação, o que faz aumentar a participação relativa de trabalhadores que não completaram o Ensino Fundamental, geralmente ocupados na construção civil, no "baixo" terciário e no mercado informal de trabalho .

De todo o modo, os resultados demonstraram que muitos municípios intermediários tiveram forte crescimento do mercado de trabalho formal nos últimos anos. Se esse mercado é um bom indicador do nível da atividade econômica, é de se esperar que esses municípios ampliem seu 
papel na reconfiguração socioespacial da rede de cidades. A mudança do padrão migratório, os novos espaços que estruturam mercados de trabalho locais e regionais, a presença de milhões de migrantes brasileiros detentores de experiências no trabalho urbano (formal e informal), introduz uma série de indagações sobre o alcance e desdobramentos dessas mudanças, o que acaba requerendo mais pesquisas capazes de esclarecer o que não é óbvio a partir de dados secundários. Daí a importância de se conhecer mais de perto algumas das cidades que vêm participando da interiorização do dinamismo econômico e demográfico no Brasil atual por meio de pesquisa direta. Uma forma de identificar as localidades a serem trabalhadas nesse tipo de pesquisa consiste na seleção do conjunto mais dinâmico de cidades intermediárias, por meio da avaliação dos dados secundários relativos à expansão demográfica e econômica. Mais dinâmicos seriam as cidades dos municípios que sustentam o crescimento demográfico e do emprego acima da média nacional por um período de tempo razoável.

\section{CIDADES MÉDIAS SELECIONADAS E ASPECTOS METODOLÓGICOS}

A seleção das cidades médias da pesquisa de campo, cada uma delas pertencentes a município com população superior a 50 mil e inferior a 750 mil habitantes no ano 2000, envolveu os seguintes outros critérios: a) estratificação dos municípios brasileiros dinâmicos, isto é: os com crescimento demográfico positivo entre 1991 e 2000 e com crescimento positivo do emprego formal na maior parte dos anos que compõem o período 1991-2000 (dados da Relação Anual de Informações Sociais - RAIS); b) Desse rol foram excluídos municípios integrantes das nove regiões metropolitanas brasileiras originais; c) também foi excluído o segundo município mais populoso integrante de uma mesma microrregião geográfica (conforme definição do IBGE). Os critérios b) e c) procuram respeitar o fator distância geográfica, a fim de selecionar cidades efetivamente polarizadoras, não afetadas diretamente pela proximidade física de uma metrópole ou centro urbano mais desenvolvido, capazes portanto de expressar de forma razoável a localização e dispersão geográfica das principais cidades médias do território brasileiro.

Restaram por fim 213 municípios, os quais foram submetidos ao sorteio estatístico para a seleção da amostra de 55 cidades que seriam trabalhados na pesquisa de campo. Entre esses 213 municípios os três de maior população urbana são Teresina (677.470 habitantes), Campo Grande (655.914) e João Pessoa (597.934). Os de menor população são Andradina (50.836), Lençóis Paulista (52.325) e Vilhena (50.601).

Para garantir que a amostra final tivesse cidades representantes de cada região, optou-se, inicialmente, por um processo de seleção considerando cada região como um estrato. Em seguida, distribuiu-se as 55 cidades (tamanho final amostra) proporcionalmente entre as regiões, considerando-se como fator de ponderação o número de cidades em cada região. Dentro de cada região (estrato) fez-se a seleção aleatória das cidades considerando-se como fatores de ponderação a taxa de crescimento demográfico e a população total de 2000. A partir de daí obtém-se o número de pessoas a serem entrevistadas em cada cidade, tendo em conta, portanto, seu tamanho populacional. As estimativas de erros, por região, possuem um nível de confiança de $95 \%$, dadas as proporções de população em cada região. O maior nível de erros situa-se em torno de $0,082(8,2 \%)$ e o menor valor é $0,034(3,4 \%)$. As estimativas de erros para todas as regiões conjuntamente é de 0,0213 $(2,13 \%)$, valor estatisticamente aceitável e similar às margens de erro das pesquisas de opinião usualmente feitas no país .

\section{Definição de quesitos de campo}

Uma vez definidas as cidades objeto da pesquisa de campo, a equipe investiu no aprimoramento do formulário amostral, no qual constaria um conjunto de questões que deveriam ser feitas aos residentes da forma mais expedita possível. Afinal, como captar a percepção da população sobre 
aspectos econômicos, culturais e geográficos em poucos minutos? A estratificação das características dos respondentes feita a priori ajudou na experiência de campo, porquanto os pesquisadores sabiam, de antemão, quantos questionários deveriam ser aplicados em cada cidade, quantos homens e mulheres deveriam compor a amostra e quais as estratégias de abordagem seriam executadas para selecionar apenas moradores alfabetizados.

Os pré-testes contribuíram para a eliminação de dúvidas, o que fez concluir que toda a pesquisa de opinião deveria ser feita exclusivamente no centro da cidade e em suas imediações (espaços de maior densidade imobiliária e de circulação de pessoas). Os freqüentadores dessas áreas representam bem a população dos residentes das cidades médias pesquisadas que, afinal, não possuem grandes periferias urbanas nem extensos centros comerciais. Os quesitos básicos do formulário de pesquisa são: sexo, idade, escolaridade, renda, ocupação, bairro onde reside, se mora em casa própria, meio de transporte utilizado, se é natural da cidade e última procedência, se for migrante.

A parte do formulário relativa à percepção individual (campos fechados da pesquisa de opinião) sobre o que a cidade oferece aos residentes baseia-se na hierarquização dos fatores que denominamos "econômico-sociais", "geoculturais" e "culturais". O entrevistado, segundo sua preferência, selecionava três cartões de um rol de 12 (fatores econômico-sociais), três outros de um rol de 14 (fatores geoculturais), e mais três cartões de um rol de 13 (fatores culturais). Em uma ultima rodada, os nove cartões selecionados eram apresentados ao entrevistado para que fizesse uma seleção final e apontasse os três mais relevantes (o formulário possui outros campos que não foram objeto de processamento estatístico dado o caráter aberto das perguntas).

\section{Fatores de fixação nas cidades médias}

A pesquisa de campo nas cidades médias selecionadas tinha uma série de objetivos gerais e específicos. Uma meta básica era consultar a população moradora sobre suas preferências na cidade, tendo em vista a seguinte orientação inicial: se as cidades eram dinâmicas, vinham experimentando mudanças econômicas e demográficas, quais poderiam ser os impactos que essas mudanças imprimiam na vida das pessoas? Alguns dos atributos das cidades médias vinham se desfazendo e tornando a qualidade de vida dos moradores pior do que antes das mudanças? Quais os fatores de tipo econômico, geocultural ou cultural poderiam ser considerados elementos de fixação dos residentes na cidade? Os migrantes, geralmente numerosos, reagiam diferentemente aos atributos da cidade?

Entendia-se que os fatores econômico-sociais, mais associados ao emprego e sobrevivência na cidade, eram dominantes, mas caberia valorizar os fatores não econômicos, e para isso, foi indispensável recorrer à longa experiência de pesquisas, debates e reorientações epistemológicas que fazem parte da Geografia Cultural, campo de conhecimentos em que é imperiosa a ligação entre espaço e cultura . Com isso tornou-se possível discernir a força dos atributos de pertencimento existentes nas cidades médias e explicar porquê a maioria das pessoas não emigra de seus municípios.

Dar voz à população, oferecendo-lhe um amplo conjunto de opções de escolha na pesquisa de opinião, foi o método escolhido referente à parte direta da pesquisa constante do formulário de campo (a outra parte compunha-se de questões abertas). Os objetivos da pesquisa e a consulta à literatura nos sugeriram reunir os fatores não econômicos em dois níveis, um mais concreto e outro mais abstrato. O primeiro, o geocultural, estabeleceria uma vinculação mais direta com elementos físico-paisagísticos, como se expressassem parte dos valores simbólicos da história e cultura do lugar, uma espécie de geografia das representações do pertencimento. O segundo, os fatores culturais, mais subjetivos e menos materiais, aludiriam a um rol de elementos que poderiam integrar a pauta de valores culturais locais, a exemplo das relações de parentesco, atividades políticas, religiosas, práticas desportivas, vida tranqüila, eventos festivos de convivência e entretenimento.

Fatores econômicos e sociais selecionados

O pressuposto nessa parte do formulário da pesquisa seria o de estimular o entrevistado a apontar elementos atrativos da cidade em que residia, já que, em outra parte do formulário, há um 
quesito que o indaga sobre aspectos críticos da cidade.

O acesso à educação e saúde, condição que certamente qualifica as melhores cidades em termos de infraestrutura, foram opções lançadas aos entrevistados, não apenas por seus significados econômicos, mas por retratar boa parte das condições sociais da vida urbana moderna. Outro conjunto de itens que se reportam a ação dos poderes públicos no espaço urbano refere-se à presença de redes de água, luz e esgoto (cartão de número 3), da mesma forma que o item "facilidade de transporte". Os demais itens do quadro abaixo são mais diversos e aludem à iniciativa privada e atributos econômicos das cidades. Facilidade de Moradia e Herança de Família podem convergir para uma mesma direção, tanto pelo preço de imóveis e aluguéis, como pela existência de patrimônio das famílias que viabiliza a permanência de parte da população na cidade. Fatores tipicamente econômicos como Emprego, Negócio Próprio, Custo de Vida Barato e Bom Salário podem representar incentivos fortes à permanência nas cidades médias. Por último, um fator geográfico, mas também econômico, é o item Perto de Tudo, a partir do qual se pode verificar a sensibilidade do entrevistado quanto às distâncias relativas. Além disso, trata-se de um fator relevante do ponto de vista urbanístico, já que a pesquisa foi desenvolvida nas áreas centrais das cidades médias, muitas delas compactas e com o centro bem desenvolvido.

\section{Fatores geoculturais}

Os fatores geoculturais selecionados procuram reunir uma série de elementos geográficos que comparecem na paisagem das cidades brasileiras. Alguns itens foram agrupados por proximidade, embora não signifiquem a mesma coisa, como "rio, lago, córrego e cachoeira". Outros são marcantes em determinadas regiões, como "praia, mar, serra". A expectativa é que os entrevistados se sentissem estimulados a apontar e hierarquizar algumas características físico-paisagísticas da cidade, com espaço no formulário para a identificação do atributo paisagístico preferido.

O fator de número 13, Casa ou Bairro onde Nasceu, o de número 21, Prédios/ Monumentos Importantes, juntamente com o de número 25, Praça/Rua/Avenida, procuram explorar imagens urbanas de expressão simbólica significativa para a população. Atributos cênicos-paisagístícos mais específicos, de função contemplativa, foram reunidos nos itens de número 17, 18, 20, 24, a saber, Rio/Lago/Córrego/ Cachoeira; Pôr do Sol/ Nascer do Sol/ Estrelas; Matas/ Bosques/ Parques/ Jardins; Belas vistas/Paisagens. Elementos integrantes da paisagem do município capazes de mobilizar pessoas para atividades lúdicas e de entretenimento foram reunidos nos itens 19 (Praia/ Mar), 22 (Serra/ Montanha), 16 (Passeios e pescarias) e 26 (Praças de esportes). O fator 14, Bom Clima, tenta indicar condições microambientais experimentadas pelos habitantes da cidade. Um último fator, que foi objeto de discussões, refere-se ao item 23, Vizinhança. A idéia de deixá-lo solto, sem articulação com outra palavra que denotasse a intenção da pesquisa, prevaleceu, embora sem uma conclusão definitiva, já que Vizinhança poderia referir-se mais diretamente aos moradores vizinhos do bairro ou da rua onde mora o entrevistado, mas poderia orientar-se para outros aspectos associados à proximidade com equipamentos públicos (penitenciária, escolas, igrejas, clubes, praças, etc.).

\section{Fatores culturais}

Os fatores culturais selecionados também foram, em parte, agrupados, para evitar o aumento em demasia dos cartões que seriam submetidas à escolha dos entrevistados. Em face da natureza da pesquisa, vários dos fatores nomeados possuem uma materialidade evidente, embora estejam impregnados de dimensões subjetivas que reportam-se à formação de culturas, hábitos e comportamentos. Os exemplos mais evidentes são Clubes ou Entidades Assistenciais; Teatro/ Cinema/ Música; Feiras Artesanais/ Barraquinhas. Alguns itens podem ser reagrupados por internalizarem certa proximidade temática. No tema "festas", estrito senso, comparecem os itens Festas Religiosas e do Padroeiro, Carnaval/Festas juninas e Danças/Cantorias. No tema "participação cívica" há os itens "Clubes ou Entidades Assistenciais"; "Prefeitura/Partido político"; "Participa de Associações, 
Conselhos ou ONGs". Nas "Práticas Religiosas, Beneméritas e Esportivas" pode-se assinalar os itens 31 (Atividades religiosas), 37 (Feiras artesanais/ Barraquinhas), 39 (Futebol/ Jogos com amigos). Para aferir se na cidade há equipamentos culturais considerados importantes pela a população ofereceu-se o cartão 34, Teatro/ Cinema/Música, como opção de escolha. "Vida tranquila/Segurança" foi um item que agregou dois aspectos não idênticos, mas bem compreendidos pela população. Da mesma forma, Apego à Família, foi de fácil entendimento para os entrevistados e revelou-se uma poderosa razão que explica a permanência dos moradores em suas respectivas cidades.

\section{RESULTADOS GERAIS}

Os resultados aqui apresentados, os primeiros da pesquisa supracitada, não ultrapassam o nível de erro amostral dos 3,4\% e 2,1\% (para todas as regiões), mantendo-se assim a referência espacial restrita ao âmbito regional, sem evoluir para o âmbito de cada cidade, onde o erro amostral aumenta.

Em termos bem gerais pode-se afirmar que a distribuição dos entrevistados por sexo, em torno de $50 \%$, se mostra bem equilibrada, assim como por idade, tendo em vista as três faixas etárias adotadas pela pesquisa. No cômputo final, os entrevistados alfabetizados possuíam, em sua maioria, o secundário completo (à exceção do Norte) e auferiam renda entre $\mathrm{R} \$ 381,00$ a $\mathrm{R} \$ 760,00$ (exceto no Norte onde prevalecem rendas mais baixas). Como esperado, a renda média das pessoas do Sudeste e Sul situava-se em níveis claramente mais elevados do que as médias de renda do Norte e Nordeste, e também do Centro Oeste. A grande maioria dos entrevistados morava em casa própria ou da família, mas cerca de $1 / 3$ dos entrevistados declararam não possuir casa própria. Os dados indicam que uma pequena maioria dos entrevistados era composta de não-naturais da cidade (cerca de $48 \%$ disseram ter nascido no município). A despeito da dificuldade de se definir objetivamente o que seja "centro da cidade", 53\% dos entrevistados que circulavam nas áreas centrais diziam morar fora do centro.

A Tabela 1 expõe os 17 principais fatores de fixação indicados pelos entrevistados residentes nas cidades médias das Grandes Regiões brasileiras. Tais fatores abrangem 3.510 entrevistas, o que representa $78,9 \%$ de todos os fatores arrolados nas 4.448 entrevistas realizadas. Os fatores com percentuais mais expressivos foram: Apego à Família (18,0\%), Educação (8,2\%), Saúde (6,5\%), Atividades Religiosas (5,4\%), Vida Tranqüila e Segurança (5,1\%), Emprego (4,9\%) e Perto de Tudo com $4,9 \%$ das indicações. Juntos, esses sete fatores integram 53,0\% das preferências dos entrevistados, enquanto os dez subseqüentes somam outros $25,8 \%$ das indicações dos 4.448 entrevistados.

Em princípio, surpreende a importância atribuída à família pela maioria dos entrevistados, em todas as regiões vis-à-vis a posição do item Emprego na hierarquia geral dos fatores. Note-se, que entre os sete fatores de fixação apontados pelos entrevistados apenas o Emprego possui uma conotação econômica muito evidente, já que os demais referem-se às dimensões cultural, institucional e geográfica. Poder-se-ia esperar que, em se tratando de cidades médias dinâmicas, o Emprego fosse o atrator mais significativo, juntamente com outros itens presentes na Tabela 1 a exemplo de Negócio Próprio e Custo de Vida.

Leituras mais acuradas dos resultados revelam a consistência das respostas dos entrevistados, inclusive expondo determinadas lógicas que não saltam aos olhos à primeira vista nas análises mais agregadas. Inicialmente, convém observar que mesmo considerando o fato de as cidades selecionadas destacarem-se em termos de emprego formal (dados da RAIS), a maioria da população ocupada ainda não possui emprego com carteira assinada. Assim, embora o item Emprego figure entre os mais relevantes não está entre os cinco principais fatores de fixação, provavelmente, porque há outros fatores mais relevantes na percepção do habitante, dotados de um caráter mais universalizante e inclusivo a exemplo de "inserção na família", acesso à educação, à saúde e às atividades religiosas. A inserção do indivíduo no mercado de trabalho formal é seletiva em muitos aspectos e depende de pré-condições econômicas e institucionais que extrapolam o mero desejo individual. Entretanto, ainda assim, é de se esperar que diante da interiorização do emprego formal no Brasil 
contemporâneo, parte dos entrevistados, mesmo não empregada, revele sensibilidade para com esse fator. Não é por outra razão que nas regiões Norte e Sul, onde muitos postos de trabalho surgiram em cidades médias nos últimos anos, foram numerosos os respondentes que valorizaram o fator Emprego, bem acima da média dos 4,9\% (7.4\% e 6,5\%, respectivamente), em visível contraste com os entrevistados das cidades nordestinas $(3,4 \%)$, onde é mais crônica a carência de empregos.

Tabela 1 -Percepção regionalizada dos moradores das cidades médias dinâmicas segundo fatores de fixação socioeconômicos, geoculturais e culturais - 2008/2009

\begin{tabular}{l|c|c|c|c|c|c}
\hline \multicolumn{1}{c|}{$\begin{array}{c}\text { Fatores de } \\
\text { Fixação }\end{array}$} & Norte & Nordeste & Sudeste & Sul & $\begin{array}{c}\text { Centro } \\
\text { Oeste }\end{array}$ & Total \\
\hline Apego à família & 13,8 & 18,3 & 18,4 & 19,7 & 15,0 & 18,0 \\
\hline Educação & $\mathbf{6 , 8}$ & 5,9 & $\mathbf{9 , 7}$ & $\mathbf{8 , 4}$ & $\mathbf{8 , 0}$ & 8,2 \\
\hline Saúde & 3,8 & $\mathbf{7 , 3}$ & $\mathbf{6 , 7}$ & $\mathbf{7 , 0}$ & $\mathbf{6 , 3}$ & 6,5 \\
\hline Atividades religiosas & 6,6 & 6,0 & 5,7 & 4,0 & 4,7 & 5,4 \\
\hline Vida tranqüila. Segurança & 6,1 & 4,8 & 5,3 & 5,1 & 4,0 & 5,1 \\
\hline Emprego & $\mathbf{7 , 4}$ & 3,4 & 4,3 & 6,5 & 4,0 & 4,9 \\
\hline Perto de tudo & 4,7 & 5,7 & 5,2 & 3,7 & 5,0 & 4,9 \\
\hline Bom clima & 2,5 & 2,3 & 4,6 & 3,8 & 6,0 & 3,8 \\
\hline Futebol, Jogos com amigos & 3,2 & 3,6 & 2,6 & 2,9 & 4,3 & 3,1 \\
\hline Negócio Próprio & 4,2 & 4,0 & 1,6 & 2,4 & 3,3 & 2,6 \\
\hline Carnaval, Festas Juninas & 4,7 & $\mathbf{6 , 3}$ & 1,3 & 1,3 & 0,7 & 2,6 \\
\hline Praia, Mar & 0,2 & 3,2 & 2,1 & 4,4 & 0,0 & 2,5 \\
\hline Custo de vida barato & 1,1 & 2,7 & 2,6 & 2,3 & 2,3 & 2,4 \\
\hline Bares, Restaurantes & 2,3 & 1,6 & 3,0 & 1,8 & 1,7 & 2,3 \\
\hline Festas religiosas e do padroeiro & 4,2 & 2,6 & 2,0 & 1,0 & 3,7 & 2,2 \\
\hline Teatro, Cinema, Música & 0,4 & 1,6 & 3,3 & 1,9 & 1,3 & 2,2 \\
\hline Água, Luz, Esgoto & 0,2 & 1,0 & 3,2 & 2,2 & 1,3 & 2,1 \\
\hline Subtotal & 72,2 & 80,4 & 81,6 & 78,1 & 71,7 & 78,9 \\
\hline Demais fatores & 27,8 & 19,6 & 18,4 & 21,9 & 28,3 & 21,1 \\
\hline Total (N. Abs.) & 472 & 878 & 1792 & 1006 & 300 & 4448 \\
\hline & & & & & & \\
\hline
\end{tabular}

Fonte: Pesquisa Direta - Leste/IGC-UFMG

No tocante aos fatores mais "universais", ao examinar regionalmente os dados, o Apego à Família apresenta-se mais expressivo nas cidades do Sul (19,7\%) - onde aspectos de coesão social e familiar associados à imigração estrangeira ainda encontram-se presentes - e menos relevantes nas cidades do Norte $(13,8 \%)$ - onde as migrações internas devem atuar na separação de parentes e familiares. Os dados da Tabela 1 sugerem que nas cidades em que os equipamentos de educação estão mais presentes (Sudeste, Sul e Centro Oeste), as indicações dos entrevistados se manifestam mais fortemente. No caso da saúde, conclusões semelhantes se aplicam a essas três regiões, embora o Nordeste surpreenda como principal destaque positivo, talvez em face da expansão significativa desse tipo de serviço nos últimos 20 anos (contrastando com a realidade de três décadas atrás), particularmente nas cidades sorteadas pela amostra. Não causa surpresa constatar que o envolvimento das pessoas em atividades religiosas se mostre mais pronunciado em regiões menos desenvolvidas como no Norte e Nordeste, secundadas pelo Sudeste $(5,7 \%)$ onde brasileiros procedentes do resto do país são muito numerosos.

Se agregados os 38 fatores em três grandes grupos, como indicado na Tabela 2, algumas das conclusões vistas acima se repetem, mas fica mais evidente a primazia dos residentes das cidades do Nordeste e Norte na valorização dos fatores culturais, a preferência dos entrevistados do Centro 
Oeste, Sul e Sudeste pelos fatores econômico-sociais, e do Norte com respeito aos fatores geoculturais, todos com percentuais superiores às médias da última coluna.

Tabela 2 - Distribuição percentual regionalizada das preferências dos residentes em cidades médias brasileiras segundo agregação dos fatores de fixação - 2008/2009

\begin{tabular}{lcccccc}
\hline \begin{tabular}{l} 
Agregação dos Fatores de \\
\multicolumn{1}{c}{ Fixação }
\end{tabular} & Norte & Nordeste & Sudeste & Sul & $\begin{array}{c}\text { Centro } \\
\text { Oeste }\end{array}$ & Total \\
\hline Fatores culturais & 42,2 & 46,4 & 41,8 & 40,9 & 39,7 & 42,4 \\
Fatores econômico-sociais & 34,5 & 36,3 & 38,0 & 39,6 & 39,3 & 37,7 \\
Fatores geoculturais & 23,2 & 17,3 & 20,2 & 19,6 & 21,0 & 19,9 \\
Total (100\%) & 469 & 877 & 1789 & 1006 & 300 & 4441 \\
\hline
\end{tabular}

Fonte: Pesquisa Direta - Leste/IGC-UFMG

As principais conclusões derivadas da Tabela 3, que expõe os 17 principais fatores de fixação segundo grupos de idade, afiguram-se bem lógicas, considerando a inserção relativa dos entrevistados nas diferentes etapas do ciclo de vida. De um modo geral os entrevistados são bastante apegados à família embora os jovens com idade entre 15 e 25 anos se declarem menos apegados que os dois outros grupos etários. Não deveria constituir surpresa o fato de o primeiro grupo, composto por muitos estudantes, ser o que mais valoriza o acesso a Educação $(38,5 \%)$, enquanto os mais velhos valorizam mais a presença de equipamentos de Saúde na cidade $(41,2 \%)$ e as atividades religiosas $(41,7 \%)$. Os dois últimos grupos etários possuem uma percepção mais aguçada que os jovens sobre a importância dos quesitos Vida tranqüila e Segurança, Festas Religiosas e do Padroeiro, Bom Clima, Negócio Próprio, Água, Luz e Esgoto. Os jovens entrevistados mostraram-se muito sensíveis a uma série de atrativos culturais existentes na cidade a exemplo de teatro, cinema, música; carnaval, festas juninas; futebol, jogos com amigos; bares, restaurantes; praia e mar. Além disso, devem valorizar a proximidade física entre esses atrativos (Perto de Tudo), embora estejam atentos em relação à oferta de emprego na cidade. Já os adultos com idade entre 26 e 50 anos parecem mais preocupados com os fatores econômicos que os demais, como se espera das pessoas nessa etapa do ciclo de vida: foram os que mais destacaram a relevância de fatores como Emprego, Negócio Próprio e Custo de Vida Barato.

A tabela 4 sintetiza as observações anteriores mediante agregação dos fatores de fixação. As conclusões mais evidentes são que, de fato, o grupo de entrevistados com idade superior valoriza mais que os dois outros grupos os fatores culturais $(43,5 \%)$, secundado pelo grupo de jovens $(42,7 \%)$. O grupo intermediário, de idade entre 26 e 50 anos, destaca-se ao apontar a relevância dos fatores econômico-sociais, enquanto para o conjunto de atributos paisagísticos da cidade não há diferença significativa na percepção dos três grupos etários, todos com resultados próximos da média dos $20 \%$. 
Tabela 3 - Percepção dos moradores das cidades médias dinâmicas segundo grupos de idade e fatores de fixação socioeconômicos, geoculturais e culturais - 2008/2009 (distribuição percentual)

\begin{tabular}{|c|c|c|c|c|}
\hline \multirow{2}{*}{$\begin{array}{c}\text { Fatores de } \\
\text { Fixação }\end{array}$} & \multicolumn{3}{|c|}{ Grupos de Idade } & \multirow{2}{*}{$\begin{array}{r}\text { Total } \\
\mathrm{N}^{\mathrm{o}} \mathrm{Abs}\end{array}$} \\
\hline & 15 a 25 & $26-50$ & Mais de 50 & \\
\hline Educação & 38,5 & 33,9 & 27,6 & 366 \\
\hline Saúde & 29,2 & 29,6 & 41,2 & 291 \\
\hline Vida tranqüila, Segurança & 26,2 & 37,1 & 36,7 & 229 \\
\hline Emprego & 40,2 & 40,6 & 19,2 & 219 \\
\hline Perto de tudo & 36,2 & 31,2 & 32,6 & 218 \\
\hline Bom clima & 28,2 & 34,7 & 37,1 & 170 \\
\hline Carnaval, Festas Juninas & 59,5 & 28,4 & 12,1 & 116 \\
\hline Praia, Mar & 40,0 & 32,7 & 27,3 & 110 \\
\hline Custo de vida barato & 33,3 & 40,0 & 26,7 & 105 \\
\hline Bares, Restaurantes & 45,5 & 26,7 & 27,7 & 101 \\
\hline Festas religiosas e do padroeiro & 19,0 & 30,0 & 51,0 & 100 \\
\hline Teatro, Cinema, Música & 64,6 & 24,2 & 11,1 & 99 \\
\hline Água, Luz, Esgoto & 26,6 & 31,9 & 41,5 & 94 \\
\hline Subtotal & 28,8 & 35,0 & 36,2 & 3510 \\
\hline
\end{tabular}

Fonte: Pesquisa Direta - Leste/IGC-UFMG

Tabela 4 - Distribuição percentual por grupos de idade das preferências dos residentes em cidades médias brasileiras segundo agregação dos fatores de fixação culturais, econômico-sociais e geoculturais - 2008/2009

\begin{tabular}{ccccc}
\hline Agregação dos Fatores de & \multicolumn{4}{c}{ Grupos de Idade } \\
Fixação & 15 a 25 & 26 - 50 & Mais de 50 & Total \\
\hline Fatores Culturais & 42,7 & 41,1 & 43,5 & 42,4 \\
Fatores Econômico-sociais & 37,5 & 39,3 & 36,3 & 37,7 \\
Fatores Geoculturais & 19,8 & 19,6 & 20,2 & 19,9 \\
\hline
\end{tabular}

Fonte: Pesquisa Direta - Leste/IGC-UFMG

A Tabela 5 expõe a percepção dos entrevistados homens e mulheres quanto aos fatores de fixação segundo status migratório (se nascido ou não nascido no município). Os principais diferenciais entre migrantes e não-migrantes podem assim ser resumidos: i) os migrantes (homens e mulheres) são claramente menos apegados à família que os naturais, mas prezam mais as atividades religiosas e, sobretudo, as oportunidades de emprego existentes na cidade, além de valorizarem mais o bom clima local e a presença de infraestrutura urbana nos setores de saúde, água, luz e esgoto; iii) os naturais homens e mulheres discrepam em termos de preferência, mas valorizam mais que os migrantes as festas populares, as festividades religiosas, o teatro, a música, o cinema, o futebol e os jogos com amigos. 
MATOS, R.

Tabela 5 - Percepção dos moradores das cidades médias dinâmicas por sexo e status migratório segundo os fatores de fixação socioeconômicos, geoculturais e culturais - 2008/2009 (distribuição percentual)

\begin{tabular}{cccccccc}
\hline Fatores de Atração & \multicolumn{3}{c}{ Mulheres } & \multicolumn{3}{c}{ Homens } & Total \\
\hline Apego à família & Não Natural & Natural & Total & Não Natural & Natural & Total & 18,0 \\
Educação & 17,6 & 22,1 & 19,8 & 13,2 & 19,4 & 16,1 & 8,2 \\
Saúde & 9,3 & 7,4 & 8,4 & 6,9 & 9,3 & 8,1 & 8,2 \\
Atividades religiosas & 7,0 & 5,5 & 6,3 & 7,3 & 6,3 & 6,8 & 6,5 \\
Vida tranqüila, segurança & 6,8 & 6,2 & 6,5 & 4,8 & 3,7 & 4,3 & 5,4 \\
Emprego & 5,3 & 5,8 & 5,5 & 5,9 & 3,5 & 4,8 & 5,1 \\
Perto de tudo & 5,6 & 3,3 & 4,5 & 7,1 & 3,4 & 5,3 & 4,9 \\
Bom clima & 5,2 & 5,1 & 5,2 & 4,5 & 4,7 & 4,6 & 4,9 \\
Futebol, jogos com amigos & 3,0 & 2,8 & 2,9 & 5,4 & 4,0 & 4,8 & 3,8 \\
Negócio próprio & 0,8 & 0,7 & 0,8 & 4,1 & 6,8 & 5,4 & 3,1 \\
Carnaval, festas juninas & 2,1 & 1,1 & 1,6 & 3,9 & 3,4 & 3,7 & 2,6 \\
Praia, mar & 1,3 & 4,7 & 2,9 & 1,1 & 3,7 & 2,3 & 2,6 \\
Custo de vida barato & 2,7 & 3,0 & 2,9 & 2,0 & 2,2 & 2,1 & 2,5 \\
Bares, restaurantes & 2,1 & 2,1 & 2,1 & 3,0 & 2,2 & 2,6 & 2,4 \\
Festas religiosas e do padroeiro & 2,5 & 2,7 & 2,6 & 2,4 & 1,4 & 1,9 & 2,3 \\
Teatro, cinema, música & 2,3 & 3,0 & 2,6 & 1,7 & 2,0 & 1,9 & 2,2 \\
Água, luz, esgoto & 2,0 & 2,4 & 2,2 & 1,9 & 2,7 & 2,3 & 2,2 \\
Subtotal & 2,1 & 1,5 & 1,8 & 2,2 & 2,6 & 2,4 & 2,1 \\
Demais fatores & 77,8 & 79,4 & 78,5 & 77,5 & 81,3 & 79,3 & 78,9 \\
& 22,2 & 20,6 & 21,5 & 22,5 & 18,8 & 20,7 & 21,1 \\
\hline
\end{tabular}

Fonte: Pesquisa Direta - Leste/IGC-UFMG

A Tabela 6 sintetiza as preferências de migrantes e não-migrantes em três níveis de agregação e indicam, de fato, que os migrantes são mais sensíveis que os não-migrantes aos fatores econômico-sociais, enquanto os naturais do município valorizam bem mais os fatores culturais. Curiosamente, os atributos paisagísticos da cidade são valorizados por ambas as populações, a despeito de serem mais destacados pelos migrantes $(20,8 \%)$.

Uma pergunta que se coloca é se os dados coletados permitem concluir sobre diferenças significativas nas preferências da população amostrada se controlados os seus níveis de renda. Apesar da não declaração da renda individual por 110 dos entrevistados é possível estabelecer algumas conclusões gerais com base nos resultados da Tabela 7. Os resultados mais interessantes apontam para uma tendência inversa em relação à preferência dos habitantes à medida que a renda aumenta ou diminui: as pessoas das faixas de maior renda individual são mais sensíveis aos fatores econômico-sociais, as de menor renda são mais apegadas aos fatores culturais. Os fatores geoculturais não exibem essa tendência de variação segundo a renda, são igualmente valorizados pelos de maior ou menor renda e os percentuais não se distanciam da média dos 19,9\%. 
Tabela 6 - Distribuição das preferências dos residentes em cidades médias brasileiras por status migratório segundo agregação dos fatores de fixação culturais, econômico-sociais e geoculturais - 2008/2009

\begin{tabular}{cccccc}
\hline Agregação dos Fatores de & \multicolumn{2}{c}{ Não Natural } & \multicolumn{2}{c}{ Natural } & \multirow{2}{*}{ Total } \\
Fixação & N. Abs. & $\%$ & N. Abs. & $\%$ & \\
\hline Fatores culturais & 903 & 38,7 & 980 & 46,4 & 42,4 \\
Fatores econômico-sociais & 944 & 40,5 & 732 & 34,7 & 37,7 \\
Fatores geoculturais & 484 & 20,8 & 398 & 18,9 & 19,9 \\
Total & 2331 & 100,0 & 2110 & 100,0 & 4441 \\
\hline
\end{tabular}

Fonte: Pesquisa Direta - Leste/IGC-UFMG

Tabela 7 - Distribuição das preferências dos residentes em cidades médias brasileiras por renda individual segundo agregação dos fatores de fixação culturais, econômico-sociais e geoculturais - 2008/2009

\begin{tabular}{|c|c|c|c|c|c|c|c|c|c|}
\hline \multirow{3}{*}{ Agregação dos Fatores de Fixação } & \multicolumn{8}{|c|}{ Faixas de Renda Individual em Salários Mínimos } & \multirow{3}{*}{ Total } \\
\hline & & & $>1 \mathrm{a}$ & $>2 \mathrm{a}$ & $>4 \mathrm{a}$ & \multirow{2}{*}{$>8$ a 16} & \multirow{2}{*}{ Mais de 16} & \multirow{2}{*}{ Não Decl. } & \\
\hline & & $>1 / 2$ a 1 & 2 & 4 & & & & & \\
\hline Fatores culturais & 43,4 & 43,9 & 43,8 & 41,2 & 38,7 & 37,9 & 36,1 & 50,0 & 42,4 \\
\hline Fat. econômico-sociais & 35,9 & 33,9 & 37,4 & 40,2 & 41,7 & 39,1 & 41,0 & 31,8 & 37,7 \\
\hline Fatores geoculturais & 20,7 & 22,3 & 18,8 & 18,6 & 19,6 & 23,0 & 23,0 & 18,2 & 19,9 \\
\hline Total & 861 & 570 & 1175 & 978 & 525 & 161 & 61 & 110 & 4441 \\
\hline
\end{tabular}

Fonte: Pesquisa Direta - Leste/IGC-UFMG

\section{REAGREGAÇÃO DOS FATORES SELECIONADOS PELOS ENTREVISTADOS}

As opções disponibilizadas aos entrevistados podem ser reagregadas segundo critérios variáveis, mas não aleatórios. Esses critérios, na verdade, se orientam para o atendimento de objetivos gerais da pesquisa, para as inferências observadas pelo pesquisador ou para questões teóricas que suscitam debates ou por políticas públicas que, em alguma medida, focalizam o espaço, os territórios e a sociedade. Uma reclassificação das 38 opções em sete itens, como se apresentará em seqüência, orienta-se, em boa medida, para as esferas da vida pública e privada.

- Os fatores de fixação à cidade associados a atividades econômicas que asseguram a sobrevivência dos residentes, dada a sua especificidade, foram reunidos em um único item denominado Emprego e Fatores Econômicos. Referem-se, na percepção do entrevistado, à presença na cidade de postos de trabalho, bons salários, custo de vida barato, facilidade de moradia, negócio próprio e heranças de família. A maioria desses itens integra-se à ordem privada, a despeito da importância dos empregos públicos em várias cidades médias.

- Família, Vizinhança e Tranquilidade exemplificariam mais claramente a dimensão do privado. Apesar da redução do tamanho das famílias no Brasil contemporâneo, seus significados múltiplos - afetivos, identitários, socioculturais e econômicos - indicam a necessidade de isolar essa dimensão, dadas a sociabilidade primária, os vínculos de lealdade e compromissos que agregam membros da família nuclear, parentes e vizinhos. Parte desses vínculos se preserva por meio de redes sociais estabelecidas no tempo, mecanismo eficiente para integrar membros da família em situações de migração, mesmo quando é grande a distância do lugar de origem.

- Educação, Saúde e Serviços Básicos representariam mais claramente a esfera pública e incorpora determinados resultados materiais da ação reguladora e dos investimentos municipais, estaduais e da União. A despeito da oferta pela iniciativa privada de serviços na área de 
saúde e educação, é predominante a presença do Estado nesses serviços, por força de garantias constitucionais e em decorrência dos investimentos efetivamente realizados na expansão das redes de saúde e educação nos últimos vinte anos nas cidades médias brasileiras. Integram-se a essa classe os serviços de infra-estrutura urbana (água, luz e esgoto), transporte e sistema viário.

- Os chamados Atrativos Paisagísticos aludem à chamada primeira e segunda natureza, reportam-se a paisagens naturais e artificiais e constituem, não raro, patrimônio público material suscetível de tombamento, dado o valor simbólico que ostentam. Alguns desses bens são de proprietários particulares não interessados em disponibilizá-los à comunidade, por ignorarem possibilidades novas trazidas pela legislação ambiental em vigor.

- Tendo em conta a importância histórica e cultural das injunções inscritas no religioso e no laico (no Brasil e no mundo) resolveu-se estabelecer uma estratificação dicotomizada que pudesse incorporar essa dimensão da vida social. Por meio das categorias Festas e Atividades Religiosas, de um lado, e Festas e Entretenimento Laico de outro, procurou-se oferecer à análise algum suporte para a observação de tendências comportamentais existentes entre os habitantes de cidades médias. É sabido que a religiosidade é um valor muito relevante na vida das pessoas em muitas cidades do interior. Entretanto, ainda assim, é plausível argüir sobre qual tem sido a representatividade das atividades laicas de entretenimento no imaginário social dos habitantes de algumas dessas cidades na atualidade .

- A participação política e cívica da população nas cidades médias brasileiras foi reunida em uma última classe juntamente com Outros .

Diante da reagregação dos fatores surgem resultados que irão ratificar conclusões anteriores, mas explicitar melhor certas dimensões da vida social nas cidades médias dinâmicas pesquisadas. Os fatores de fixação reagrupados estão dispostos nas tabelas que se seguem, segundo a importância que possuem no total geral. A observação das respostas dos moradores distribuída regionalmente indica que: a) nas regiões Sul e Sudeste "apego à família, vizinhança e tranqüilidade" sensibilizaram os entrevistados mais que a média geral dos $24,9 \%$ (por si só bastante alta); b) A presença dos investimentos públicos na "educação, saúde e serviços básicos" é bastante valorizada pelos respondentes. Os dados mostram claramente a supremacia do Sudeste e a fragilidade do Norte e Nordeste, e a percepção dos residentes coincide com diversas estatísticas disponíveis baseadas em dados secundários; c) Os "atrativos paisagísticos” surpreendem. Estatísticas sobre esses atributos são desconhecidas no país e, ao que tudo indica, os entrevistados valorizam significativamente as dimensões materiais existentes em suas cidades que evocam beleza, espairecimento e conforto mental. Isso é particularmente notável no Norte e Sul, embora em todas as regiões as respostas alcancem percentuais próximos dos $15 \%$; d) O "emprego e fatores econômicos" são valorizados pelos entrevistados, sobretudo se forem abundantes na cidade, o que nem sempre se verifica, como já observamos. De toda maneira, a reagregação dos fatores aqui efetuada, põe em destaque as regiões Norte, Centro Oeste e Sul, com percentuais acima da média geral, o que confere com tendências apontadas em resultados do item anterior; e) É bem provável que a pesquisa de campo tenha trazido à luz um outro achado: as "festas e entretenimento laico" tornaram-se mais relevantes para os habitantes das cidades médias que as "festas e atividades religiosas". Isso se mostrou mais intenso nas cidades visitadas das regiões Nordeste, Norte e Centro Oeste (e mesmo no Sudeste), não obstante a importância da religião na vida das pessoas dessas mesmas regiões. As explicações mais profundas para essas evidências abrangem inúmeros aspectos, muitos dos quais ultrapassam o arco de investigação desse estudo. 
Tabela 8 - Distribuição percentual regionalizada das preferências dos residentes em cidades médias brasileiras segundo reagregação dos fatores de fixação - 2008/2009

\begin{tabular}{cccccccc}
\hline Fatores de Fixação Agregados & & Nor- & Su- & & \multicolumn{2}{c}{$\begin{array}{c}\text { Centro } \\
\text { Oeste }\end{array}$} & Total \\
& Norte & & & Sul & \\
& & Deste & deste & & 24,3 & 24,9 \\
Apego a família, vizinhança e tranquilidade & 22,2 & 24,3 & 25,7 & 26,1 & 22,3 & \\
Educação, saúde e serviços básicos & 17,2 & 21,0 & 26,6 & 24,0 & 23,3 & 23,7 \\
Atrativos paisagísticos & 18,2 & 14,6 & 15,2 & 16,3 & 16,0 & 15,7 \\
Emprego e fatores econômicos & 17,2 & 15,0 & 11,3 & 15,6 & 15,7 & 13,9 \\
Festas e entretenimento laico & 12,7 & 14,2 & 11,3 & 10,3 & 10,3 & 11,7 \\
Festas e atividades religiosas & 10,8 & 8,9 & 8,1 & 5,5 & 9,3 & 8,0 \\
Participação política, cívica e outros & 1,7 & 2,1 & 1,8 & 2,2 & 3,0 & 2,0 \\
\hline
\end{tabular}

Fonte: Pesquisa Direta - Leste/IGC-UFMG

De toda a forma, as preferências dos entrevistados distribuídas segundo grupos de idade (Tabela 9) auxiliam no entendimento das constatações vistas acima, desde que se atente para a complexidade dos aspectos que envolvem as mudanças demográficas que a população brasileira vem experimentando (com o avanço progressivo do "envelhecimento" até pelo menos meados do século XXI). Tais mudanças interferem nos estilos de vida e padrões comportamentais de populações em diferentes etapas do ciclo de vida, em face dos contextos de modernidade e de encurtamento do tempo-espaço.

Tabela 9 - Distribuição percentual das preferências dos residentes em cidades médias brasileiras segundo grupos de idade e reagregação dos fatores de fixação - 2008/2009

\begin{tabular}{cccccc}
\hline Fatores de Fixação Agregados & \multicolumn{4}{c}{ Grupos de Idade } & Total \\
& 15 a 25 & $26-50$ & Mais de 50 \\
& & & & \\
\hline Apego à família, vizinhança e tranquilidade & 22,0 & 25,7 & 27,1 & 24,9 \\
Educação, saúde e serviços básicos & 23,5 & 22,6 & 25,0 & 23,7 \\
Atrativos paisagísticos & 15,5 & 16,4 & 15,2 & 15,7 \\
Emprego e fatores econômicos & 13,8 & 16,7 & 11,1 & 13,9 \\
Festas e entretenimento laico & 18,2 & 9,0 & 7,9 & 11,7 \\
Festas e atividades religiosas & 5,8 & 7,5 & 10,9 & 8,0 \\
Participação política, cívica e outros & 1,1 & 2,1 & 2,8 & 2,0 \\
\hline
\end{tabular}

Fonte: Pesquisa Direta - Leste/IGC-UFMG

Os dados ratificam conclusões anteriores e apontam sinteticamente que: i) o grupo mais velho valoriza mais que os dois outros a família, a vizinhança, a tranqüilidade, a educação, a saúde, os serviços básicos, as festas e atividades religiosas, além de ser o mais sensível à participação política e cívica; ii) os entrevistados mais jovens possuem uma percepção bem mais aguçada do que os outros grupos etários para as "festas e entretenimento laico", embora não deixem de valorizar o item "educação, saúde e serviços básicos" (particularmente a educação, como já visto), o "emprego e fatores econômicos" e os atrativos paisagísticos geoculturais; iii) o grupo intermediário, com idades entre 26 e 50 anos, focaliza mais os fatores econômicos, sem deixar de valorizar a família, a vizinhança, a tranqüilidade, os atrativos paisagísticos e as festas laicas.

As preferências diferenciadas entre os naturais e não naturais do município (Tabela 10) reafirmam conclusões anteriores e deixam mais claras as diferenças entre essas sub-populações. De fato, os naturais - especialmente as mulheres - são mais propensos a valorizar a família, a vizinhança e a tranqüilidade que os migrantes, os quais também não deixam de considerá-los fatores importantes, mesmo que separados de parte de suas famílias. Como já observado, os migrantes são mais sensí- 
veis ao "emprego e fatores econômicos" da cidade e às "festas e atividades religiosas", enquanto os naturais preferem as "festas e o entretenimento laico". Curiosamente, os atrativos paisagísticos são mais percebidos pelos migrantes homens e pelas mulheres não-migrantes, enquanto a "educação, saúde e serviços básicos" são mais apontados como relevantes pelas mulheres migrantes e pelos homens não-migrantes.

Tabela 10 - Distribuição percentual das preferências dos residentes em cidades médias brasileiras por sexo e status migratório segundo reagregação dos fatores de fixação - 2008/2009

\begin{tabular}{|c|c|c|c|c|c|c|c|}
\hline \multirow{2}{*}{ Fatores de Fixação Agregados } & \multicolumn{3}{|c|}{ Mulheres } & \multicolumn{3}{|c|}{ Homens } & \multirow{2}{*}{$\begin{array}{l}\text { Total } \\
\text { Geral }\end{array}$} \\
\hline & Não Natural & Natural & Total & Não Natural & Natural & Total & \\
\hline Apego a família, vizinhança e tranquilidade & 26,0 & 29,7 & 27,8 & 20,8 & 23,5 & 22,1 & 24,9 \\
\hline Educação, saúde e serviços básicos & $\underline{25,7}$ & 21,3 & 23,6 & 23,2 & $\underline{24,4}$ & 23,8 & 23,7 \\
\hline Atrativos paisagísticos & 14,9 & 15,7 & 15,3 & $\underline{16,8}$ & 15,4 & 16,1 & 15,7 \\
\hline Emprego e fatores econômicos & 13,3 & 10,5 & 12,0 & $\underline{18,5}$ & 13,0 & 15,9 & 13,9 \\
\hline Festas e entretenimento laico & 8,8 & 11,5 & 10,1 & 11,1 & $\underline{16,0}$ & 13,4 & 11,7 \\
\hline Festas e atividades religiosas & $\underline{9,5}$ & 9,4 & 9,5 & 7,2 & 5,9 & 6,6 & 8,0 \\
\hline Participação política, cívica e outros & 1,9 & 2,0 & 1,9 & 2,3 & 1,9 & 2,1 & 2,0 \\
\hline
\end{tabular}

Fonte: Pesquisa Direta - Leste/IGC-UFMG

\section{2}

\section{CONSIDERAÇÕES FINAIS}

Nos últimos dez anos o emprego com carteira assinada vem se expandindo em centros urbanos de porte intermediário em todas as regiões do país. Há um processo de desconcentração econômica e demográfica em curso, mais ou menos intenso conforme as sub-regiões e o período focalizado. Os fluxos migratórios vêm assumindo novas direções nos últimos 30 anos, embora o ritmo dessa redistribuição populacional não seja acompanhado pelo ritmo (mais lento) da redistribuição do emprego. Dentre as atividades que respondem pelo dinamismo das cidades médias, a indústria, a agroindústria e os investimentos públicos constituem um sustentáculo do processo de interiorização da atividade econômica.

Os dados indicam que vários municípios intermediários têm ampliado seu papel na rede de cidades. Os novos padrões da migração interna, os milhares de trabalhadores migrantes com experiência profissional em áreas urbanas e as novas tendências espaciais do emprego formal apontam a necessidade de aprofundamento de pesquisas capazes de auxiliar o entendimento de uma série de novas e antigas questões. Afinal, como reage a população das cidades médias dinâmicas que participam da interiorização econômica e demográfica no Brasil atual?

Identificadas essas localidades por meio de dados secundários sobre crescimento demográfico e do emprego formal e obedecidos os critérios que privilegiaram a localização geográfica dispersa regionalmente, chegou-se, mediante sorteio, a 55 cidades que foram objeto de pesquisas de campo entre os anos de 2008 e 2009. A parte do formulário específica à pesquisa de opinião indagava os residentes sobre a importância relativa dos fatores de fixação (na cidade) aqui discriminados em três grupos: os econômico-sociais, os geoculturais e os culturais. Se agregadas as 38 possibilidades de respostas dos entrevistados, fica evidente a primazia dos fatores culturais sobre os demais, particularmente entre os residentes das cidades das regiões Nordeste e Norte. Os fatores econômico-sociais comparecem em seqüência e são mais relevantes para os residentes do Centro Oeste, Sul e Sudeste, enquanto os fatores geoculturais são significativos para cerca de $20 \%$ dos entrevistados em quase todas as regiões. 
Os resultados obtidos evidenciam que os residentes de mais idade valorizam muito os fatores culturais e geoculturais, enquanto o grupo dos adultos com idade entre 26 e 50 anos aponta os fatores econômico-sociais como mais relevantes. Os mais jovens, embora não se destaquem nas proporções de preferências como os dois outros grupos etários, não deixam de assinalar a importância dos fatores culturais e econômico-sociais, nessa ordem.

Se os dados mostraram a existência de diferenciais nas preferências dos entrevistados por idade, sexo e região, a mesma tendência se verifica controlando a condição migratória e a renda dos respondentes? Ao que tudo indica os migrantes percebem mais agudamente os fatores econômico-sociais que os não-migrantes, enquanto esses últimos valorizam bem mais os fatores culturais. Os diferenciais por renda individual foram significativos, porquanto as pessoas de maior renda mostraram-se mais sensíveis aos fatores econômico-sociais, enquanto as de menor renda preferem os fatores culturais. Já os atributos paisagísticos (fatores geoculturais) foram, no cômputo geral, igualmente valorizados tanto por migrantes e não-migrantes, quanto pelos mais ricos e pelos mais pobres.

A importância atribuída à família pela maioria dos entrevistados diante do item Emprego chega a surpreender tendo em conta o caráter dinâmico das cidades selecionadas. Análises mais detalhadas revelam, entretanto, a consistência dos resultados, já que mesmo tendo em mente que a maioria dos que trabalham não possui carteira assinada, nas regiões onde houve mais expansão do emprego formal, como no Norte e Sul, os entrevistados apontaram mais enfaticamente a relevância do fator Emprego.

De todo o modo, há fatores que são mais valorizados na percepção do habitante, talvez por internalizarem um caráter mais universalizante e não-excludente tais como apego a família, acesso à educação, à saúde e à religião. É razoável concluir, com base no sentimento cultural das pessoas em relação aos lugares em que vivem: que o acesso à saúde e educação são culturas da modernidade bem assimiladas por todos. Somam-se a antigas tradições culturais existentes no mundo inteiro associadas à família e à religião. Então, se é verdade que a população encontra-se mais próxima das atividades religiosas em regiões menos desenvolvidas, como no Norte e Nordeste, parece não haver dúvidas sobre o valor que atribuem à presença de equipamentos de saúde e educação, em qualquer região do país.

Os fatores de fixação ao serem reagregados em sete classes mostraram-se hierarquicamente relevantes na seguinte ordem: "Apego à família, vizinhança e tranqüilidade"; "Educação, saúde e serviços básicos"; "Atrativos paisagísticos"; "Emprego e fatores econômicos"; "Festas e entretenimento laico"; "Festas e atividades religiosas"; "Participação política, cívica e outros".

$\mathrm{O}$ "apego à família, vizinhança e tranqüilidade" continua sendo um item relevante para os habitantes, especialmente se residirem no Sul e Sudeste, assim como é expressiva a percepção dos fatores de fixação associados a "educação, saúde e serviços básicos". Na reagregação dos fatores, os "atrativos paisagísticos" surpreendem, assim como as preferências em relação aos eventos laicos e religiosos. Mesmo que sejam raras as estatísticas sobre tais itens no país, não há duvidas de que se referem à componentes sensíveis da percepção da população das cidades médias. A valorização das paisagens urbanas e naturais pode estar em sintonia com a valorização das "festas e entretenimento laico", já que ambos atuam no imaginário das pessoas. A despeito dos diferenciais por sexo, idade e renda, e do respeito à religião, os moradores das cidades médias estão preferindo as festividades laicas às "festas e atividades religiosas".

Ficam, ainda, evidentes os diferenciais entre migrantes e não-migrantes. Apesar de os atrativos paisagísticos serem percebidos como importantes por ambas as populações. Os naturais da cidade, principalmente as mulheres, valorizam mais a família, a vizinhança e a tranqüilidade. Enquanto os migrantes orientam-se principalmente para o "emprego e fatores econômicos" e preferem as "festas e atividades religiosas", os naturais do município preferem as "festas e o entretenimento laico". 
Esse trabalho procura contribuir com os estudos da Geografia Cultural brasileira a partir de uma perspectiva transdisciplinar. Para isso é mister: a) considerar que, a despeito da forte visibilidade dos movimentos migratórios e de suas diversas teorias explicativas, a não-migração é predominante e quase nunca é mencionada nos estudos sobre cidades e vida urbana; b) a explicação teórica para a não-migração extrapola os fatores tipicamente econômicos e exige atenção para com dimensões identitárias e de pertencimento que constroem vínculos entre lugares e pessoas (objeto de pesquisa antigo da Geografia Cultural mundial); c) atributos paisagísticos e socioculturais, além dos tipicamente econômicos, podem ser arrolados entre os fatores que mais explicam a fixação da população nas localidades em que vivem; d) pesquisas diretas que auscultem diretamente a população, inventariando suas preferências espaciais podem ser expeditas e representam um mecanismo de aprofundamento da democracia da consulta aplicável em qualquer lugar e em centenas de localidades em curto espaço de tempo.

Finalmente, a despeito de tantas novas perguntas que poderiam ser arroladas diante dos resultados indicados pela pesquisa, algumas recomendações sobre cidades médias dinâmicas brasileiras podem ser listadas em seqüência, todas elas passíveis de discussões e debates até serem convertidas em políticas públicas abrangentes espacialmente. Sugere-se a reunião de esforços voltados à:

i) realização de projetos de preservação e revalorização de bens patrimoniais naturais e artificiais dotados de alto valor simbólico e paisagístico reconhecido pelos residentes, mediante coordenação local integrada por lideranças comunitárias e representantes do poder público;

ii) o aproveitamento, pelas administrações públicas municipal e regional, dos migrantes de retorno possuidores de habilitações demandadas pela município, com vistas à promoção do desenvolvimento econômico e social;

iii) o aprimoramento de programas habitacionais nos municípios que experimentam dinamismo demográfico e econômico, mediante parcerias interinstitucionais e participação de segmentos da população, com vistas ao incremento da cidadania e da auto-estima local.

\section{REFERÊNCIA BIBLIOGRÁFICA}

BONNEMAISON, J. Viagem em Torno do Território/ Geografia Cultural: Um Século. In: ROSENDAHL, Z. e CORREAA, R. L. (Orgs). Geografia Cultural: Um Século. Rio de Janeiro: EdUERJ, 2002.

BRAUDEL, F. Tempo do Mundo; civilização material, economia e capitalismo. São Paulo. Martins Fontes. 1996.

CLAVAL, P. La Geographie Culturelle. Paris. E. Nathan, 1995.

CORRÊA, R. L. Carl Sauer e a Geografia Cultural. Revista Brasileira de Geografia. 51 (1). 1989, 113-122. CORREAA, R. L. e ROSENDAHL, Z (Orgs). Introdução a Geografia Cultural. Rio de Janeiro. Bertrand Brasil, 2003.

COSGRove, D. A Geografia está em Toda Parte: Cultura e Simbolismo nas Paisagens Humanas. ROSENDAHL, Z; CORREAA, R. L. (Orgs). Paisagem, Tempo e Cultura. Rio de Janeiro: EdUERJ, 1998.

GALLAIS, J. Alguns aspectos do espaço vivido nas civilizações do mundo tropical. In: ROSENDAHL, Z. e CORREAA, R. L. (Orgs). Geografia Cultural: Um Século. Rio de Janeiro: EdUERJ, 2002.

GOMES, P. C. da C. Geografia e modernidade. Rio de Janeiro: Bertrand Brasil, 1996.

HARVEY, D. Condição Pós-Moderna. São Paulo: Loyola, 1996.

LOWENTHAL, D. Geography, Experience and Imagination: Towards a Geographical Epistemology. In: CHRISTOFOLETTI, A. Perspectivas da Geografia. São Paulo: DIFEL, 1982, pp.103-141.

MATOS, R. E. S.; FERREIRA, R. N. Inserção ocupacional de emigrantes das Áreas Metropolitanas de São Paulo e Rio de Janeiro. Revista Brasileira de Estudos da População, Campinas, v. 21, n. 1, p. 83-100, 2004. 
MATOS, R. E. S. (Org.). Espacialidades em Rede: População, Urbanização e Migração no Brasil Contemporâneo. Belo Horizonte: C/Arte Editora, 2005. 264 p.

McDOWELL, L. A transformação da geografia cultural. In: GREGORY, D; MARTIN, R; SMITH, G. (Orgs.). Geografia humana; sociedade, espaço e ciência social. Rio de Janeiro: Jorge Zahar, 1996.

SAUER, Carl O. Geografia cultural. Espaço e cultura. Rio de Janeiro, n. 3, dez. 1996.

SORRE, MAX. A Noção de Gênero de Vida e Seu Valor Atual. In: ROSENDAHL, Z. e CORRÊA, R. L. (Orgs). Geografia Cultural: Um Século. Rio de Janeiro: EdUERJ. 2000.

TUAN, YI - Fu. Espaço e lugar. São Paulo, DIFEL, 1983.

Trabalho enviado em janeiro de 2013

Trabalho aceito em fevereiro de 2013 